\title{
Analysis on Dynamic Decision-Making Model of the Enterprise Technological Innovation Investment under Uncertain Environment
}

\author{
Yong Long, ${ }^{1}$ Hongwei $\mathrm{Wu}^{1}{ }^{1}$ and Ke Qiucheng $\mathrm{Zhou}^{2}$ \\ ${ }^{1}$ College of Economics and Business Administration, Chongqing University, Chongqing 400044, China \\ ${ }^{2}$ School of International Business, Beijing Language and Culture University, Beijing 100083, China
}

Correspondence should be addressed to Hongwei Wu, hongweiwu678@yahoo.cn

Received 19 September 2012; Accepted 29 November 2012

Academic Editor: Jian-Wen Peng

Copyright (c) 2012 Yong Long et al. This is an open access article distributed under the Creative Commons Attribution License, which permits unrestricted use, distribution, and reproduction in any medium, provided the original work is properly cited.

Under the environment of fuzzy factors including the return of market, performance of product, and the demanding level of market, we use the method of dynamic programming and establish the model of investment decision, in technology innovation project of enterprise, based on the dynamic programming. Analysis of the influence caused by the changes of fuzzy uncertainty factors to technological innovation project investment of enterprise.

\section{Introduction}

The enterprise technological innovation is a creative process. The uncertainty risk mainly includes the environment, technology, market, and risk management. At the same time, the process of enterprise technological innovation is a dynamic process. In the initial stage of the technical innovation, the enterprise must evaluate and select the innovation project and also consider the social and economic benefits and the development of technology with the combination of their own development strategies; at the end select the most suitable for the development of innovative investment projects. Sarkar [1] had studied market uncertainty and corporate investment relationship in consideration of system risk conditions, and he thinks that increasing the uncertainty may increase the probability of investment of enterprises to some low growth and low risk of investment project. In fact, a technical innovation project can be regarded as embedded in a series of options chain, and each option gives investors investment rights, so every decision stage contains an "improvement option"; when the difficult technology problem definitely is solved, we can make further investment in product prototype development and innovative design and then continue investing to enter the testing phase. At the same time, in every decision stage there is an abandonment option, so the flexibility of project management not only increases the value of the project, but also reduces 
the investment risk of the technical innovation project. Weeds [2] described if research and development is successful as a Poisson process, and it is used to describe the uncertainty of technology and of Hershey's bad market opportunity arrival timing. He builds two stages' $R \& D$ investment pricing model and discusses the reality of "Sleeping Patent" rationality; that is, the enterprise is willing to develop a technology, but after the success of the technology research and development, will put it away unheeded and not put it into the market. Mitchell and Hamilton [3] point out that due to R\&D plays an important role in creating competitive advantage and, therefore, should be treated from a strategic perspective, discussing in detail the multiple features of the R\&D strategic options and then taking three steps: clear strategic aim, evaluation strategy options, and select influence strategic target to study R\&D strategy option. Lint and Pennings $[4,5]$ mainly studied the innovation of real option in the process of marketization and pointed out that there were two choices, disposable rapid advancing, and slow advancing and related options opportunities and options value hid in slow advancing. Huchzermeier and Loch [6] proposed a decision model of multiple stages and considered in each phase of this model that managers had three solutions: continue to invest in the project, improve the project, and give up the project. From the market returns, assumed total return consists of two levels: a basic income can be relatively easy to be obtained; only in the project performance exceeding market demands becomes uncertain. They also identified several different sources of the flexibility and uncertainty and made analysis of the impact problem increased by uncertainty and flexibility. From the characteristics that the state variable of $R \& D$ project is a nonfinancial parameter, using an equivalent method, dynamic planning of the option evaluation to build the dynamic programming model of R\&D project, without the need for asset replication, Sheng [7] had solved the flexible problem of R\&D project well.

The aforementioned is the study conducted under random environment (some discrete environmental). In fact, the essence of fuzzy real option is that tolerance in the same information shows diversification before the rationality and that the complexity of the human mind is admitted, namely, the introduction of nonuniform rational in the value assessment. At the same time, there are often still some realities that we cannot accurate valuation or expect net cash flow situation and due to objective factors some variables cannot be estimated by the exact data, and some actual situation etc (Liu [8]). So evaluation results often deviate from the actual if we use the accurate values to determine model input parameters. In this paper, we mainly combine the dynamic programming method and option analysis method, in a fuzzy environment making an analysis of some flexible decision problems of enterprise technology innovation and innovation investment. Firstly the Huchzermeier and Loch [6] model is extended. Secondly a discussion of dynamic programming model of the second stage under fuzzy environment is made. Thirdly analysis is made about technological innovation project decision model under fuzzy environment. Then the elastic value of the project of technology innovation is discussed. It focuses on the analysis of changes of the fuzzy uncertainty factors (including market returns and demanding level).

\section{The Dynamic Programming Decision Model of the Technological Innovation Investment under Fuzzy Environment}

\subsection{Extending of Huchzermeier and Loch Model}

Under the fuzzy environment, we consider a technical innovation project; the success of the project depends mainly on the performance of the products during commercialization in the market, and the fuzzy uncertainty of market performance is caused by market and technology 
risk, denoted by $(i, t)$ project at time $t$ expected market performance (the market performance can be expected through the simulation test, get). Typically managers have difficulty to predict the distribution of $i$ during the stage of outcome of the market commercialization, assuming $i$ as fuzzy variables and $i$ obeying credibility distribution; the expected profits of the maximum and minimum values are $Q$ and $q$, respectively, actual process of project meets no aftereffect, and the state transfer of market performance obeys two distribution; if the products of the project development reach to the performance state $i$, the expected profit is

$$
\pi_{i}=q+\Phi(i)(Q-q) \quad(\Phi(i) \text { is credibility distribution function }) .
$$

By Liu [8], in the processing of fuzzy event, credibility measure plays a similar role in the probability measure on random events. So, modeled as stochastic events in the transition probability, in the evaluation model of two-fork tree option, assuming the state transfer of market performance obeys two distributions, namely, the condition of market upgraded by the credibility of $\operatorname{Cr}\{A\}$, and under adverse conditions turning for the worse with probability $(1-\operatorname{Cr}\{A\})$, we generalize this process as the market's performance improvement and deterioration and then easily conclude that the transition probability $P_{i j}$ is expressed as follows under fuzzy environment:

$$
P_{i j}= \begin{cases}\frac{\operatorname{Cr}\{A\}}{N}, & j \in\left(i+\frac{1}{2}, \ldots, i+\frac{N}{2}\right), \\ \frac{1-\operatorname{Cr}\{A\}}{N}, & j \in\left(i-\frac{1}{2}, \ldots, i-\frac{N}{2}\right), \\ 0, & \text { other. }\end{cases}
$$

At the same time, while expanding the scale of investment, under fuzzy environment the transition probability is

$$
P_{i j}= \begin{cases}\frac{\operatorname{Cr}\{A\}}{N}, & j \in\left(i+1+\frac{1}{2}, \ldots, i+1+\frac{N}{2}\right) \\ \frac{1-\operatorname{Cr}\{A\}}{N}, & j \in\left(i+1-\frac{1}{2}, \ldots, i+1-\frac{N}{2}\right) \\ 0, & \text { other. }\end{cases}
$$

Under fuzzy environment, the project management dynamic programming optimal value function, in the last stage of commercial stage project:

$$
V_{i}(T)=\max \begin{cases}-C(T)+\frac{\sum_{j}^{N}\left[\operatorname{Cr}\{A\} \pi_{i+j / 2}+(1-\operatorname{Cr}\{A\}) \pi_{i-j / 2}\right]}{N(1+r)} & \text { continue, } \\ -C(T)-A(T)+\frac{\sum_{j}^{N}\left[\operatorname{Cr}\{A\} \pi_{i+1+j / 2}+(1-\operatorname{Cr}\{A\}) \pi_{i+1-j / 2}\right]}{N(1+r)} & \text { improvement, } \\ 0 & \text { give up, }\end{cases}
$$


where $C(T)$ is the cost of project's continuation and $A(T)$ are the cost when the project is increased in size, including the net present value of option strategic: $V=V(0)-I$; theoretically speaking, fuzzy environment is closer to the reality of the technical innovation. So, this model has certain practical significance, of course, according to the difference of the actual investment situation; we also can extend the model to the fuzzy random environment, fuzzy environment, rough fuzzy environment, and so forth.

\subsection{The Dynamic Programming Model of the Two Stages under Fuzzy Environment}

Assuming $I$ is sunk cost, the interest rate without the risk is $r>0$, and $u, d$ are parameters; hypothesize; the price of the product in stage 0 is $P_{0}$, from the beginning of stage 1 , the feasibility of the prices $(1+u) P_{0}$ is $\operatorname{Cr}\{A\}$, the feasibility of the prices of $(1-d) P_{0}$ is $(1-\operatorname{Cr}\{A\})$, assuming that the investment opportunity lies only in stage 0 ; if the technical innovation enterprises do not invest at this stage, so in stage 1, it will not change the decision forever; we use $V_{0}$ to be the symbol for the expectation value obtained from its investment of technology innovation enterprise, then

$$
\begin{aligned}
V_{0} & =P_{0}+\left[\operatorname{Cr}\{A\}(1+u) P_{0}+(1-\operatorname{Cr}\{A\})(1-d) P_{0}\right]\left[\frac{1}{1+r}+\frac{1}{(1+r)^{2}}+\cdots\right] \\
& =\frac{P_{0}[1+r+\operatorname{Cr}\{A\}(u+d)-d]}{r} .
\end{aligned}
$$

Now, we consider the reality of the situation; in any future stage, the investment opportunities still exist. So, at this time, in stage 0 , we can choose to invest or wait to select until stage 1 ; from stage 1 forward conditions will not change; if in phase 1 waiting, the price becomes

$$
P_{1}= \begin{cases}(1+u) P_{0}, & \text { when the feasibility of } \operatorname{Cr}\{A\} \\ (1-d) P_{0}, & \text { when the feasibility of } 1-\operatorname{Cr}\{A\}\end{cases}
$$

To either possibilities (price changing in stage 0 and stage 1 ), if $V_{0}>I$, then enterprise invests, we can get the net return: $F_{1}=\max \left\{V_{1}-I, 0\right\}$.

The discounted value is $V_{1}=P_{1}(1+r) / r$; from stage 0 , the price is $P_{1}$ in stage 1 , the value is $V_{1}, F_{1}$ is the random variables, and $E_{0}$ is the expected value calculated by feasible weighted average in stage 0 , then

$$
\begin{aligned}
E_{0}\left(F_{1}\right)= & \operatorname{Cr}\{A\} \max \left[\frac{(1+u) P_{0}(1+r)}{r}-I, 0\right] \\
& +(1-\operatorname{Cr}\{A\}) \max \left[\frac{(1-D) P_{0}(1+r)}{r}-I, 0\right] .
\end{aligned}
$$

Back to stage 0 , the enterprise has two kinds of choices. If it invests, the income is $V_{0}-I$; if not, the enterprise has continuous value $E_{0}\left(F_{1}\right)$, but the value is obtained in stage 1 , 
so it should use $1 /(1+r)$ to discount; therefore, the whole investment opportunities are the net present value of the investment profit arranged optimally, credited as $F_{0}$

$$
F_{0}=\max \left\{V_{0}-I, \frac{1}{1+r} E\left(F_{1}\right)\right\}
$$

Previously we discussed the dynamic programming model in Sheng [7] under fuzzy environment. Theoretically speaking, the fuzzy environment is closer to the technical innovation in reality, so this model has certain practical significance. Below we start from Liu [8] model, combine Dixit and Pindyck [9], and make discussion about the multistage model.

\subsection{The Decision Model of Technological Innovation Project during Multistages under Fuzzy Environment}

\subsubsection{Fuzzy Uncertainty of Technological Innovation Project during Development Stage}

Investment management of technical innovation project is a decision process of multistages. Each stage has decision points of project evaluation. Each decision point includes the project evaluation at present, investment decision making of the current state, and future earnings evaluation based on each kind of decision-making choice. In this section, we use the fuzzy theory proposed by Liu [8] to handle uncertainty of technical innovation project's development phase. Firstly the decision model of technology innovation project during multistage is described [7].

\section{Santiago and Vakili Model}

Assuming totally there are $T$ stages of decision making of technology innovation project, $t=0,1,2, \ldots, T-1$, in each stage $t$, decision makers will face three alternatives, "continue" "improvement," and "give up". The success of technical innovation project depends on the performance of the product put into market; we use the state variables of the project to show the product performance in the process of the development. Let the $X_{t}$ project be the state variables in the initial stage $t$, and assume when $t=0, X_{0}=0 ; \xi_{t}$ is the fuzzy uncertainty of the project inside and outside during $t$ stage in the process of innovation, and $\left\{\xi_{0}, \xi_{1}, \ldots, \xi_{T-1}\right\}$ are independent from each other; $u_{t}$ is the choice decision of the project in stage of starting time. So, when the $t$ stage is completed, the state variable of project can be expressed as [10]

$$
X_{t+1}= \begin{cases}X_{t}+k\left(u_{t}\right)+\xi_{t}, & \text { if } u_{t} \text { choose "continue" or "improvement", } \\ X_{t}, & \text { if } u_{t} \text { choose to "give up", }\end{cases}
$$

where the feasibility of $k$ (continue) $=0$ and $k$ (improvement) $=1$ is $\operatorname{Cr}\{A\} / N$, the feasibility of $\xi_{t}=-i / 2$ is $(1-\operatorname{Cr}\{A\}) / N, i=1,2, \ldots, N, N$ is regarded as a measure of the uncertainty and fuzziness. In other words, if the item "continues," then in the next stage, the expected performance will be present together with some fuzzy uncertainty; if the item "improves," the project of state variable will be plused one more improved unit and fuzzy uncertain effects; if the project "gives up", the project stops at current state variables and remains unchanged. According to the discussion of Sheng [7], we have the following 


\section{Nature 1}

A decision-making problem of a technical innovation project is considered under fuzzy environment:

$$
X_{t}= \begin{cases}X_{t}^{\prime}, & \text { if choose "continue" or "improvement", } \\ X_{t}, & \text { if choose to "give up". }\end{cases}
$$

According to hypothesis at the initial time of $t$ stage, the state variables of project in two cases are $X_{t}$ and $X_{t}^{\prime}$, respectively, and $X_{t}$ and $X_{t}^{\prime}$ are fuzzy variables on possibility space $(\Theta, P(\Theta)$, Pos $)$, then, $X_{t} \geq X_{t}^{\prime}$.

Proof. Assume in two cases that the initial state variables of project equal, that is, $X_{0}=X_{0}^{\prime}=0$, because $X_{t}$ and $X_{t}^{\prime}$ are fuzzy variables of $(\Theta, P(\Theta)$, Pos) on possibility space. According to hypothesis in $t-1$ phase, for all $\theta \in \Theta$, we have $X_{t-1}(\theta) \geq X_{t-1}^{\prime}(\theta)$. Assume in $t-1$ phase situation 1 , decision makers take $u^{*}$ as the optimal decision, and then in the $t$ stage by Santiago and Vakili [10] model, we can get

$$
X_{t}(\theta)=X_{t-1}(\theta)+k\left(u^{*}\right)+\xi_{t-1}(\theta) \geq X_{t-1}^{\prime}(\theta)+\xi_{t-1}(\theta)=X_{t}^{\prime}(\theta), \quad \text { then } X_{t} \geq X_{t}^{\prime} .
$$

\subsubsection{Fuzzy Expected Value, Variance}

The fuzzy uncertainty of technical innovation project $\xi_{t}(t=0, \ldots, T-1)$ includes the technical risk of the project development process inside and the fuzziness influenced by the external environment, though there is statistical data of the project of the same type for reference, because technical innovation project is unique and singular, which makes subjective judgment of decision makers essential. We describe this kind of fuzzy uncertainty as fuzzy variable, which is independent and identically distributed, and its expected value is 0 . It indicates that the project performance may be improved due to favorable fuzzy uncertain events, and also may be worse due to the occurrence of adverse; by assumptions of Yi Chang sheng, the fuzzy variable $\xi_{t}$ expectations of the technological innovation project are expressed as

$$
E\left[\xi_{t}\right]=\int_{0}^{+\infty} \operatorname{Cr}\left\{\xi_{t} \geq r\right\} d r-\int_{-\infty}^{0} \operatorname{Cr}\left\{\xi_{t} \leq r\right\} d r=0
$$

According to Liu $[8]$ and $E(\xi)=0$, then the variance is $V\left[\xi_{t}\right]=E\left[\left(\xi_{t}-E\left[\xi_{t}\right]\right)^{2}\right]$. The variance of $V\left[\xi_{t}\right]$ can be used as a measure of fuzzy degree of uncertainty of technical innovation project. If $V\left[\xi_{t}\right]$ is smaller, then the fuzzy uncertainty is smaller. The solvent of fuzzy uncertainty can be reflected by the cumulative value of technical innovation project. Assumed in the of the initial state item variables is $X_{t}$, at the end of $t$ phase and the initial time of $t+1$ stage, the fuzzy uncertain factors $\xi_{t}$ of $t$ phase are solved, and the state variables of project will change to $X_{t}+k\left(u_{t}\right)+\xi_{t} \cdot \xi_{t}$ shows the fuzzy uncertainty of the project in the phase under internal and external environment. It includes the technical risk during the process of project development, the evaluation of the project's profitability made by the project team, the external market information of project, and other aspects. 


\subsubsection{Development Costs and Market Returns}

According to the model of Huchzermeier and Loch [6], because during the development process of each stage of the development cost and decision-making choices, we can assume the project in phase $t$ development costs as $C_{t}\left(u_{t}\right)$; if the decision maker chooses "give up," then the cost of project development is 0 . If the decision maker selects "continue," then the cost of project development is $c(t)$ (the "continue" cost of $c(t)$ for stage $t$ ); if the decision maker selects "improvement," then the cost of project development is $c(t)+a(t)(a(t)$ is the additional cost invested when taking corrective action and does not need to extend the project schedule, such as processing engineers and the experimental equipment; it can make the project status variables improve a unit). If project's initial investment is $I$ while $t=0$, the revenue and cost of project discount according to the nonrisk free rate $r$. At the end of $t-1$ phase, the project is completed and products are put into market, enterprises will get market gains closely related to product performance, and $R\left(X_{T}\right)$ expressed as follows:

$$
R\left(X_{T}\right)= \begin{cases}m, & \text { if } X_{T}<\eta, \\ M, & \text { if } X_{T} \geq \eta,\end{cases}
$$

where $\eta$ is the market's demand level of the product and $X_{T}$ is the state variable after $t-1$ stage is over, that is, the final product performance obtained by enterprise. If the product's performance meets or exceeds $\eta$, then the business has more advantages than its competitors in product performance and will gain a perfect profit of $M$; conversely, the enterprise can only get a small profit of $m$ (clearly, $m<M$ ); because the $\eta$ is unknown before the product entering market, we postulate it is the fuzzy variable. For any $\theta \in \Theta$, assums the variable is $X_{T}(\theta)$ during project phase, we use $\operatorname{Cr}\left\{X_{T}(\theta) \geq \eta\right\}$ to show that project state variable $X_{T}(\theta)$ reaches or exceeds the credibility of $\eta$; then, when the state variable is $X_{T}(\theta)$, the expected value of fuzzy market returns is

$$
\begin{aligned}
E\left[\Pi\left(X_{T}\right)\right] & =\int_{0}^{+\infty} \operatorname{Cr}\left\{R\left(X_{T}(\theta)\right) \geq r\right\} d r \\
& =\int_{0}^{m} \operatorname{Cr}\left\{R\left(X_{T}(\theta)\right) \geq r\right\} d r+\int_{m}^{M} \operatorname{Cr}\left\{R\left(X_{T}(\theta)\right) \geq r\right\} d r \\
& =m+\int_{m}^{M} \operatorname{Cr}\left\{X_{T}(\theta) \geq \eta\right\} d r \\
& =m+\operatorname{Cr}\left\{X_{T}(\theta) \geq \eta\right\} \int_{m}^{M} d r \\
& =m+\operatorname{Cr}\left\{X_{T}(\theta) \geq \eta\right\}(M-m) .
\end{aligned}
$$

We use $\phi(\cdot)$ to show credibility distribution function of the fuzzy variable $\eta$, then

$$
E\left[\Pi\left(X_{T}\right)\right]=m+\phi\left(X_{T}\right) \cdot(M-m) .
$$


Huchzermeier and Loch [6] show the benefit function: if the performance level is $X_{T}$ at the moment of $T$, it will generate the expected market return $\Pi_{i}$. According to the different actual investment situations, we can also extend the conclusion to fuzzy random environment, rough fuzzy environment, and so on. For example, under fuzzy random environment, when the variables of product state are $X_{T}(\theta)$, the expectation obtained by fuzzy stochastic market returns $\Pi\left(X_{T}\right)$ can also be presented in this way.

Definition 2.1. Let $\xi$ be a fuzzy random variable, and then one has a finite expected value $E(\xi)$, $V[\xi]=E\left[(\xi-E[\xi])^{2}\right]$ that is called fuzzy variable $\xi$ variance.

From the previous discussion, when the product state variable is $X_{T}(\theta)$, the expectation of fuzzy stochastic market returns $\Pi\left(X_{T}\right)$ is obtained by

$$
\begin{aligned}
E\left[\Pi\left(X_{T}\right)\right] & =\int_{0}^{+\infty} \operatorname{Pr}\left\{\xi \in \Omega \mid R\left(X_{T}(\theta)\right) \geq r\right\} d r \\
& =\int_{0}^{m} \operatorname{Pr}\left\{\xi \in \Omega \mid R\left(X_{T}(\theta)\right) \geq r\right\} d r+\int_{m}^{M} \operatorname{Pr}\left\{\xi \in \Omega \mid R\left(X_{T}(\theta)\right) \geq r\right\} d r \\
& =m+\int_{m}^{M} \operatorname{Pr}\left\{\xi \in \Omega \mid R\left(X_{T}(\theta)\right) \geq r\right\} d r \\
& =m+\operatorname{Pr}\left\{\xi \in \Omega \mid X_{T}(\theta) \geq r\right\} \int_{m}^{M} d r \\
& =m+\operatorname{Pr}\left\{\xi \in \Omega \mid X_{T}(\theta) \geq r\right\}(M-m) .
\end{aligned}
$$

Therefore, a double-fuzzy environment and rough fuzzy environment are similar to be launched.

\subsubsection{The Dynamic Programming Model of Technological Innovation Project}

We consider the decision behavior of the enterprise technology innovation investment; the project current state variable is indicated by $x$, it will affect opportunities of the enterprise's decision-making and expansion, at any stage of $t$, and the value of variable $x_{t}$ is known, let the future value $x_{t+1}, x_{t+2}, \ldots$ be random variables. $\left\{x_{t}\right\}$ is Markov process; we use the $V_{t}(x)$ to be the whole decision results of company from $t$; when selecting $u_{t}$ as the control variables, its cash flow is $\Pi_{t}\left(x_{t}, u_{t}\right)$, at the phase of $t+1$, the state is $x_{t+1}$, the result of optimal decision result is $V_{t+1}\left(x_{t+1}\right)$; at the phase of $t$, this result is a random variable, so, we take $E\left(V_{t+1}\left(x_{t+1}\right)\right)$ as expected value, discounting to the stage of $t$; the plus of sight cash flow and the continuous value is

$$
\Pi_{t}\left(x_{t}, u_{t}, \xi_{t}\right)+\frac{1}{1+\rho} E\left(V_{t+1}\left(x_{t+1}\right)\right)
$$

Enterprises will choose $u_{t}$ to be maximum, and the result just is $V_{t}\left(x_{t}\right)$; then we have

$$
V_{t}\left(x_{t}\right)=\max _{u_{t}}\left\{\Pi_{t}\left(x_{t}, u_{t}\right)+\frac{1}{1+\rho} E\left(V_{t+1}\left(x_{t+1}\right)\right)\right\} .
$$

This equation is the optimal basic equation (see [9]). 
If multiple phase problems have limited stage $T$, the ultimate returns of enterprises are $\Omega_{T}\left(x_{t}\right)$; then in the previous stage, we have

$$
V_{T-1}\left(x_{T-1}\right)=\max _{u_{T-1}}\left\{\Pi_{T-1}\left(x_{T-1}, u_{T-1}\right)+\frac{1}{1+\rho} E\left(\Omega_{T-1}\left(x_{T-1}\right)\right)\right\},
$$

which provides theoretical basis to simulate by using computer.

In fact, the $x_{t}, x_{t+1}$ may be in any state, and it can be generally denoted as $x, x^{\prime}$; then, for any $x$, we have Bellman equation of infinite duration dynamic programming:

$$
V(x)=\max _{t}\left\{\Pi(x, u)+\frac{1}{1+\rho} E\left(V\left(x^{\prime}\right) \mid x, u\right)\right\} .
$$

In the following we put this problem to further discussion under fuzzy environment.

Technical innovation project is on the stage of development spending is by the final market returns to compensate for an evaluation, according to the Santiago and Vakili model, since each choose temporary investment costs are known, therefore, management decision based primarily on the final market assessment. We use the value of the function $V_{t}(x)$ to be this evaluation, fuzzy uncertainty $\xi_{t}(t=0, \ldots, T-1)$ of technical innovation project includes the technical inside risk of the project during the development process, and the uncertainty influenced by external environment, and $\xi_{t}$ is fuzzy variable independent and identically distributed, and its expected value is 0 . Assuming in the stage that the development cost is $C_{t}\left(u_{t}\right)$, according to Santiago and Vakili model, it can be described by dynamic programming equation:

$$
V_{t}\left(x_{t}\right)=\max _{u_{t}}\left\{-C_{t}\left(u_{t}\right)+\frac{1}{1+r} E\left[V_{t+1}\left(X_{t+1}\left(x_{t}, u_{t}, \xi_{t}\right)\right)\right]\right\}
$$

Value of the function is $V_{t}(x)$ at $t$ phase; initial project state variable is $x$. At the end of the project phase of $t=T$, we have

$$
V_{t}(x)=E[\Pi(x)]
$$

At the same time, under fuzzy environment, if multiple phase problems have limited stage $T$, the ultimate returns obtained by the enterprises are $\Omega_{T}\left(x_{t}\right)$; at an earlier stage, we have

$$
V_{T-1}\left(x_{T-1}\right)=\max _{u_{T-1}}\left\{-C_{T-1}\left(u_{T-1}\right)+\frac{1}{1+\rho} E\left[V_{T}\left(\Omega_{T}\left(x_{T-1}, u_{T-1}, \xi_{T-1}\right)\right)\right]\right\} .
$$

In fact, $x_{t}, x_{t+1}$ may be any state, it can be generally written as $x, x^{\prime}$; and then for any $x$, we have Bellman equation of infinite duration dynamic programming under fuzzy environment:

$$
V(x)=\max _{t}\left\{-C(x, u, \xi)+\frac{1}{1+\rho} E\left(V\left(x^{\prime}\right) \mid x, u, \xi\right)\right\}
$$


The discussion of Santiago and Vakili [10] and Sheng [7] also gives a property of value function under the stochastic uncertainty environment; the following is the promotion under fuzzy environment.

\section{Nature 2}

Assuming the technology innovation project of state variables is indicated by $x$ under fuzzy environment, if the expected market return function $E[\Pi(x)]$ is nondecreasing, then the value of the function $V_{t}(x)(t=0,1, \ldots, T-1)$ of technical innovation project in any stage is nondecreasing too.

Proof. In reference Santiago and Vakili [10], if $V_{t+1}(x)$ is non-decreasing, we assume that $V_{t+1}(x)$ is nondecreasing; for two project state variables $x_{1}$ and $x_{2}$ of a given $t$ phase, if $x_{2}>x_{1}$, then we only need to prove $V_{t}\left(x_{2}\right) \geq V_{t}\left(x_{1}\right)$. Assuming that at $t$ phase, the project of state variable is $x_{1}$, selecting the optimal decision $u^{*}$, makes the enterprise obtain the maximum $V_{t}\left(x_{1}\right)$. When the state variable of $t$ phase is $x_{2}$, the taken decisions $u^{*}$ make enterprises get the project value $V_{t}^{\prime}\left(x_{2}\right)$; then consider the following;

(1) If $u^{*}$ is "continue" or "improved," we have

$$
\begin{aligned}
V_{t}^{\prime}\left(x_{2}\right)-V_{t}\left(x_{1}\right)= & \max _{u_{t}}\left\{-C_{t}\left(u_{t}\right)+\frac{1}{1+r} E\left[V_{t+1}\left(X_{t+1}\left(x_{2}, u_{t}, \xi_{t}\right)\right)\right]\right\} \\
& -\max _{u_{t}}\left\{-C_{t}\left(u_{t}\right)+\frac{1}{1+r} E\left[V_{t+1}\left(X_{t+1}\left(x_{1}, u_{t}, \xi_{t}\right)\right)\right]\right\} \\
= & \frac{1}{1+r} E\left[V_{t+1}\left(x_{2}+k\left(u^{*}\right)+\xi_{t}\right)-V_{t+1}\left(x_{1}+k\left(u^{*}\right)+\xi_{t}\right)\right] .
\end{aligned}
$$

(2) If $u^{*}$ is "gives up." $V_{t}^{\prime}\left(x_{2}\right)-V_{t}\left(x_{1}\right)=0$. Because $\xi_{t}$ is a fuzzy variable, so, $x_{1}+$ $k\left(u^{*}\right)+\xi_{t}$ and $x_{2}+k\left(u^{*}\right)+\xi_{t}$ are fuzzy variables. If $x_{2}>x_{1}$, we have $x_{1}+k\left(u^{*}\right)+\xi_{t}>$ $x_{2}+k\left(u^{*}\right)+\xi_{t}$. Because $V_{t+1}(x)$ is monotonicity, we have

$$
V_{t+1}\left(x_{2}+k\left(u^{*}\right)+\xi_{t}\right)-V_{t+1}\left(x_{1}+k\left(u^{*}\right)+\xi_{t}\right) \geq 0
$$

From the properties that the fuzzy variable is nonnegative, and its expected value is also non-negative, we have

$$
E\left[V_{t+1}\left(x_{2}+k\left(u^{*}\right)+\xi_{t}\right)-V_{t+1}\left(x_{1}+k\left(u^{*}\right)+\xi_{t}\right)\right] \geq 0 .
$$

Therefore, $V_{t}^{\prime}\left(x_{2}\right)-V_{t}\left(x_{1}\right) \geq 0$. When the status of technical innovation project is $x_{2}$, the maximum value of technology innovation obtained, and the makers' optimal decision is $V_{t}\left(x_{2}\right)$, so we have $V_{t}\left(x_{2}\right) \geq V_{t}^{\prime}\left(x_{2}\right)$.

Therefore, $V_{t}\left(x_{2}\right)-V_{t}\left(x_{1}\right) \geq V_{t}^{\prime}\left(x_{2}\right)-V_{t}\left(x_{1}\right) \geq 0$, that is, $V_{t}\left(x_{2}\right) \geq V_{t}\left(x_{1}\right)$. 


\section{Nature 3}

From the aforementioned, we also can get that under fuzzy environment, if the optimal decision selected by the decision maker is "give up," when the state variable is $x$ during the state of $t$ and when the variable is less than $x$, the optimal decision is "give up" too.

\section{Conclusion}

Combining the dynamic programming method and option analysis method, we make analysis of flexible decision problems of enterprise technological innovation investment, under fuzzy environment, mainly introducing fuzzy factors based on the model of Huchzermeier and Loch [6], Santiago and Vakili [10], Dixit and Pindyck [9], Sheng [7], and so forth. We establish the model, focus on the promotion of the Huchzermeier and Loch model under fuzzy environment, establish models of two-phase, multi-stage dynamic programming decision and make some analysis, and then draw valuable conclusions. But it only extends the models of Huchzermeier and Loch and Santiago and Vakili [10] to the fuzzy environment; in fact, this kind of promotion can also be extended to the fuzzy random environment and rough fuzzy environment. Although some attempt has been made, it is still not enough. This is what we should try our best in during the next step.

\section{References}

[1] S. Sarkar, "On the investment-uncertainty relationship in a real options model," Journal of Economic Dynamics and Control, vol. 24, no. 2, pp. 219-225, 2000.

[2] H. Weeds, "Sleeping patents and compulsory licensing: an options analysis," Working Paper, Fitzwilliam College, University of Cambridge, 1999.

[3] G. R. Mitchell and W. F. Hamilton, "Managing R\&D as a strategic option," Research Technology Management, vol. 50, no. 2, pp. 41-50, 2007.

[4] O. Lint and E. Pennings, "R\&D as an option on market introduction," RED Management, vol. 28, no. 4, pp. 279-287, 1998.

[5] E. Pennings and O. Lint, "Market entry, phased rollout or abandonment? A real option approach," European Journal of Operational Research, vol. 124, no. 1, pp. 125-138, 2000.

[6] A. Huchzermeier and C. H. Loch, "Project management under risk: using the real options approach to evaluate flexibility in R\&D," Management Science, vol. 47, no. 1, pp. 85-101, 2001.

[7] Y. C. Sheng, Under the uncertain environment project decision analysis [Doctoral Dissertation], Tianjin University, 2006.

[8] B. Liu, Uncertainty Theory, vol. 154 of Studies in Fuzziness and Soft Computing, Springer, Berlin, 2nd edition, 2007.

[9] A. K. Dixit and R. S. Pindyck, Investment under Uncertainty Princeton, Princeton University, Princeton, NJ, USA, 1994.

[10] L. P. Santiago and P. Vakili, "On the value of flexibility in R\&D projects," Management Science, vol. 51, no. 8, pp. 1206-1218, 2005. 


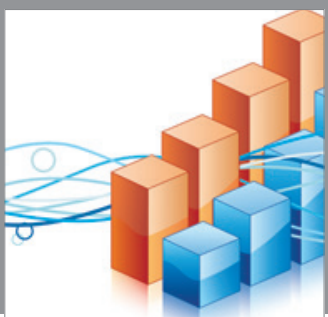

Advances in

Operations Research

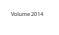

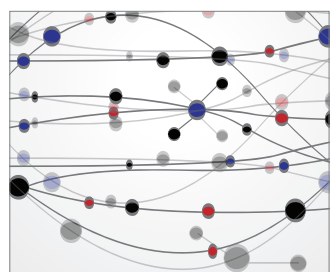

\section{The Scientific} World Journal
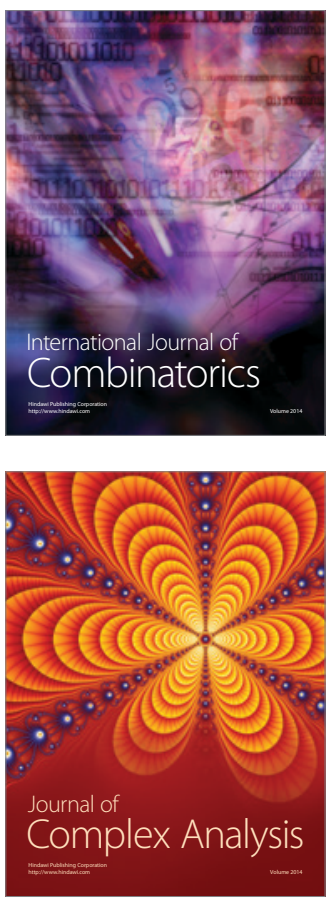

International Journal of

Mathematics and

Mathematical

Sciences
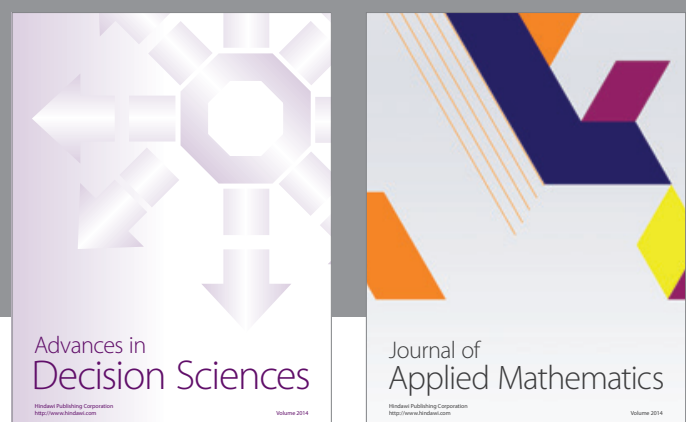

Journal of

Applied Mathematics
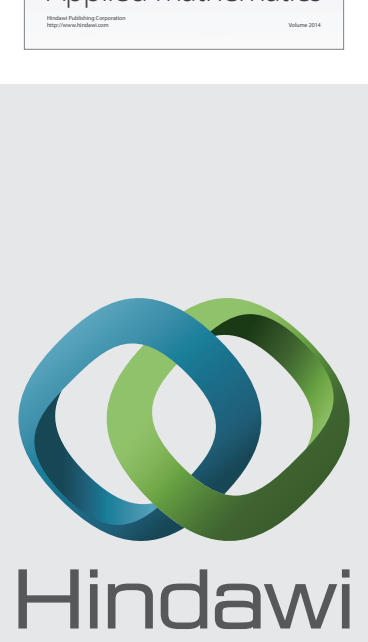

Submit your manuscripts at http://www.hindawi.com
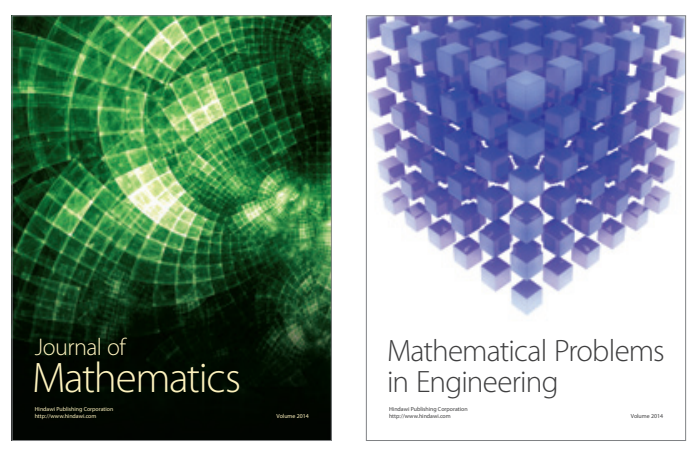

Mathematical Problems in Engineering
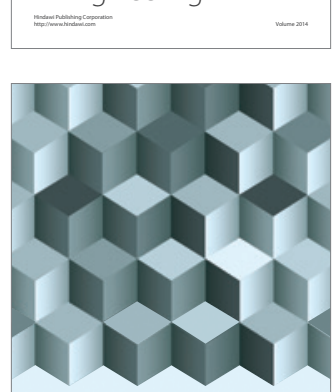

Journal of

Function Spaces
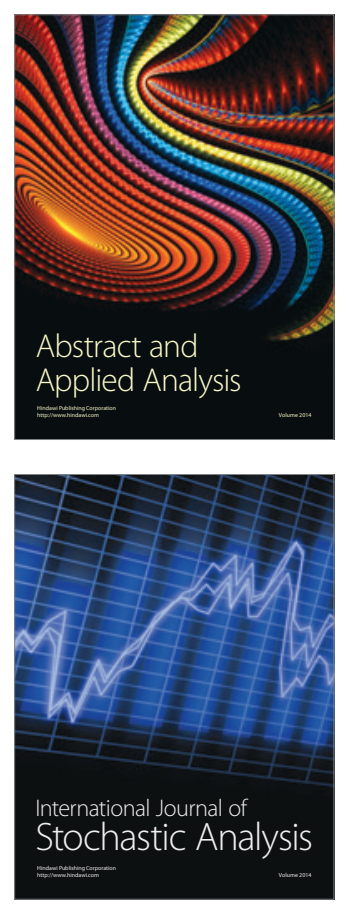

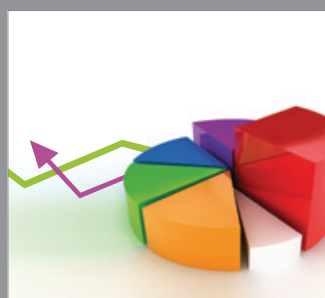

ournal of

Probability and Statistics

Promensencen
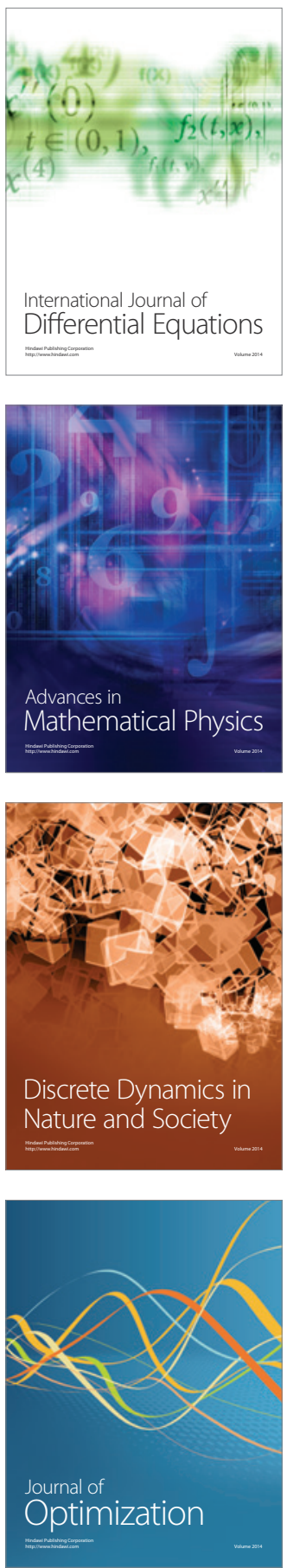